\title{
Cultural Differences in the Association of Harsh Parenting with Internalizing and Externalizing Symptoms: A Meta-Analysis
}

\author{
Martin Pinquart (iD)
}

Accepted: 9 September 2021 / Published online: 8 October 2021

(c) The Author(s) 2021

\begin{abstract}
The goal of the present meta-analysis was to compare associations of harsh parenting with internalizing and externalizing symptoms across regions of the globe and ethnic groups, and to search for moderator effects of indicators of cultural normativeness of harsh parenting. The systematic search in electronic databases and cross-referencing identified 971 studies. Random-effects meta-analyses were computed on bivariate and cross-lagged associations. Harsh parenting was associated with more internalizing and externalizing symptoms in all assessed regions of the globe and in all compared ethnic groups within western countries. Cross-lagged statistical effects of harsh parenting on change in child symptoms were found in North America, Western Europe, Latin America, East Asia, South-East Asia, and North Africa/the Arabian Peninsula, while there were no data from Eastern Europe. In line with the cultural normativeness hypothesis, a few moderating effects of the legal ban of physical punishment of children, acceptance and prevalence of physical punishment, and individualismcollectivism were identified. Externalizing symptoms predicted a stronger increase in harsh parenting if physical punishment was more accepted in the individual country. However, national levels of acceptance of physical punishment did not affect associations of harsh parenting with change in child outcomes. Although most associations of harsh parenting with child symptoms were statistically small (bivariate associations) or very small (cross-lagged associations), it is concluded that parents across the globe should be recommended to avoid harsh parenting. More longitudinal studies are needed for analyzing regional differences in parent and child effects.
\end{abstract}

Keywords Harsh discipline $\cdot$ Corporal punishment $\cdot$ Spanking $\cdot$ Internalizing symptoms $\cdot$ Externalizing symptoms

\section{Highlights}

- Parenting effects varied, in part, by the cultural normativeness of the parental behavior.

- Harsh parenting was associated with more child symptoms across the globe, and in different ethnic groups.

- Externalizing symptoms predicted stronger increases in harsh parenting in countries where physical punishment is more accepted.

- Cultural acceptance of physical punishment did not moderate association of harsh parenting with change in externalizing symptoms.

- Similarly, cultural acceptance did not moderate association of harsh parenting with internalizing symptoms.

Supplementary information The online version contains supplementary material available at https://doi.org/10.1007/s10826021-02113-z.

Martin Pinquart

pinquart@staff.uni-marburg.de

1 Department of Psychology, Philipps University, Marburg, Germany
Data from UNICEF (2019) indicate that most children in Africa (82.5\%) and Asia (76.8\%) have experienced violent discipline (physical punishment or psychological aggression) in the last month. Rates were lower in Eastern Europe (63.5\%) and Latin America (63.3\%). A study from the US indicated that $80 \%$ of mothers of 6-year-olds have spanked their child (Gershoff et al., 2012). Severe forms of physical punishment tend to be less common than milder forms. For example, a study by Manzoni and Schwarzenegger (2019) asked $7^{\text {th }}, 8^{\text {th }}$, and $9^{\text {th }}$ graders from 26 countries whether one 
of their parents ever hit them with an object, punched them, kicked them forcefully, or beat them up. Rates were highest in Venezuela (15.8\%), Indonesia (13.4\%), and Cape Verde (12.9\%) and lowest in Denmark (2.6\%) and Kosovo (2.0\%). A study with university students from 32 nations on perceived acceptance of physical punishment asked whether it is sometimes necessary to discipline the child "with a good harsh spanking." While only $15 \%$ of the Swedish participants agreed, agreement rates of above $90 \%$ were found in South Korea and Singapore (Straus, 2010, p. 17). About 83\% of Western European countries, 67\% of Eastern European countries, $27 \%$ of Central and South American countries, $18 \%$ of Subsahara African countries, $11 \%$ of North African countries/the Arabian Peninsula, and 6\% of Asian countries have legally banned all physical punishment of children by their parents (Global Initiative to End Corporal Punishment of Children, 2020). Nonetheless, physical punishment that does not cause harm or injury is still allowed in many countries, such as the United States (Global Initiative to End Corporal Punishment of Children, 2020; Miller-Perrin \& Perrin, 2018). In sum, physical punishment of children tends to be least normative in Western Europe and most normative in Africa, the Arab Peninsula, and Asia (see also, Dwairy et al., 2006; Wang \& Liu, 2018)

As physical punishment and negative verbal behavior of parents towards their children often cooccur, many studies use combined measures of overall harsh parenting (Hinnant et al., 2015). The term harsh parenting refers to coercive acts and negative emotional expressions of parents towards their children. It includes verbal aggression, such as yelling or name calling, and physical aggression, such as slapping, spanking, or beating up (Hinnant et al., 2015). Harsh parenting can be conceptualized along a continuum from acts causing minimal psychological and/or psychological pain to child maltreatment which causes serious injury or even death of the child (Gershoff, 2002). A number of meta-analyses have shown that harsh parenting in general (Pinquart, 2017a, b) and physical punishment in particular (Ferguson, 2013; Gershoff \& Grogan-Kaylor, 2016a; Larzerle et al., 2018) are concurrently associated with higher levels of externalizing and internalizing symptoms in children and adolescents, and that harsh parenting and physical punishment predict an increase in these symptoms over time. However, most of the included studies have been conducted in the US or in other western countries, and within Caucasian families. For example, in the meta-analysis by Gershoff and Grogan-Kaylor (2016a), 69.4\% of the included effect sizes came from the US, and part of the remaining studies were from Western Europe. Thus, it has not been systematically tested whether associations of harsh parenting and child outcomes are the same across all regions of the globe.

It has been suggested that associations between harsh parenting and child outcomes vary depending on whether this behavior is culturally accepted (the cultural normativeness hypothesis; Deater-Deckard \& Dodge, 1997; Lansford et al., 2005; Liu \& Wang, 2018; Rohner et al., 1996). The basic assumption is that children interpret parental behavior in relation to the behavior of other parents in their community or culture, and react more positively towards normative parental behavior (that is accepted and prevalent in their culture) than towards other behaviors (Grusec \& Goodnow, 1994; Deater-Deckard \& Dodge, 1997). Applied to physical discipline, Lansford et al. (2005) suggested that physical punishment will have negative effects on child outcomes if it is perceived as nonnormative while it will have no negative effect if perceived as culturally normative. Similarly, Wang and Liu (2018, p. 175) proposed that in traditional Chinese societies, parental harsh discipline may be accepted because both parents and children perceive this behavior as indicators of parental involvement, concern, and love, as indicated by a Chinese proverb, which states "Beating and scolding is the emblem of love." Under this condition, harsh parenting would not cause adjustment problems in the offspring. In western countries, such as the US or Western Europe, children may perceive harsh discipline as a sign of parental rejection, which may cause, again, anger and hostility in the child with accompanying opposition (Lansford et al., 2005; Lansford \& Dodge, 2008, Rohner et al., 1996; Wang \& Liu, 2018). Nonetheless, cultural acceptance of physical punishment or harsh parenting in general may not necessarily lead to weaker associations of these parental behaviors with child outcomes. More concretely, a decline in the acceptance of harsh parenting, such as physical punishment, is expected to lead to a lower prevalence of this behavior in general and of severe forms in particular (Janson et al., 2010). Severe forms of physical punishment have been found to show stronger associations with child outcomes than milder forms (Ferguson, 2013). If only few cases with milder forms of harsh punishment persist in a country in response to low cultural normativeness, variance restriction may lead to small associations with child outcomes.

Cultural normativeness could also play a role when addressing effects of children's behavior problems on harsh parenting. Several theoretical models suggest that dysfunctional parenting and children's problem behaviors reinforce each other (Bell, 1977; Reid et al., 2002). For example, if harsh parenting is more culturally accepted, parents may be more likely to use physically punishment after their child misbehaved because of expecting that physical punishment is appropriate for preventing future externalizing problems.

Available cross-national studies provided only partial support for the suggestion that indicators of normativeness moderate the size of the association of harsh parenting with child outcomes. A comparative study of associations between corporal punishment and behavior problems in six 
countries found the weakest association between maternal use of physical punishment and parental reports about children's behavior problems in the countries in which corporal punishment was most prevalent and probably most culturally accepted (i.e., India, Kenya). However, no such difference was found when using child reports about anxiety and aggressive behavior as outcome variables (Lansford et al., 2005). Manzoni and Schwarzenegger (2019) found the strongest association between physical punishment and externalizing problems in the country with the lowest prevalence rate of this form of punishment (i.e., Kosovo). However, in the country with the highest prevalence rate (i.e., Venezuela), the association of physical punishment and externalizing problems was not below the average of all included 26 countries. A meta-analysis by Gershoff and Grogan-Kaylor (2016a) did not find differences between the results of studies from the US and those from outside the US, but the cultural normativeness hypothesis would indicate strongest differences between Western European countries and countries from Africa and Asia. Unfortunately, these studies did not directly test whether indicators of cultural normativeness explain national differences in the association of harsh parenting with child outcomes.

Three sources of information can be used on national differences in the acceptance of harsh parenting - crossnational surveys that assessed perceptions of normativeness of these parenting practices (Strauss, 2010), comparative studies on their actual use (actual normativeness, such as Manzoni \& Schwarzenegger, 2019), and data on whether harsh parenting has been legally banned in individual countries (legal normativeness, Global Initiative to End Corporal Punishment of Children, 2020). With regard to cultural acceptance, some authors have suggested that the national level of collectivism-individualism might indicate whether mild forms of physical punishment are culturally appropriate for promoting obedience (Ifan, 2008; Rudy \& Grusec, 2006). In collectivist cultures, individuals are integrated into strong in-groups (e.g., the nuclear family) with emphasis on cohesiveness and harmony, and in-group members protect each other in exchange for unquestioning loyalty (Hofstede et al., 2010). In this cultural context, power-assertive parental behaviors, such as mild forms of spanking, are acceptable for promoting obedience (Ifan, 2008; Rudy \& Grusec, 2006). In contrast, more individualistic cultures promote independence of the individual (Hofstede et al., 2010), and harsh parenting hinders the development of child's sense of autonomy (Grusec \& Goodnow, 1994).

Cultural differences in the acceptance and use of harsh parenting also exist within countries, such as between ethnic groups. Ethnic groups are linked by a shared culture and social heritage (Gershoff \& Grogan-Kaylor, 2016b). African-American parents tend to report higher levels of spanking and to perceive spanking as more appropriate compared to European American parents (Geshoff et al., 2012; Lee \& Watson, 2020; Silveira et al., 2021). Nonetheless, a meta-analysis by Gershoff and Grogan-Kaylor (2016b) did not find differences in the association of spanking with child outcomes between African-American and European American families. However, the test power was limited due to inclusion of only five studies. A metaanalysis has not yet addressed whether associations of harsh parenting and child outcomes differ between Caucasian, Hispanic, and Asian families. Comparisons of the use of harsh parenting by European American and Hispanic parents led to inconsistent results which varied by level of acculturation (Geshoff et al., 2012) and cohort membership (Taillieu et al., 2014), thus indicating that there is also variability within ethnic groups. Studies found that Chinese-American mothers have more positive attitudes towards spanking than Caucasian mothers (Mah \& Johnston, 2012) and that Asian-Canadians use more physical punishment than Caucasian Canadians (Fréchette \& Romano, 2015). However, a study by Gershoff et al. (2012) indicated similar rates of spanking and similar associations of spanking with externalizing problems in Asian-American and Caucasian American families. Differences in the ethnic composition of the samples may explain inconsistent results as Silveira et al. (2021) found higher rates of physical punishment in British-Asian (mainly Pakistani, Bangladeshi, Indian) parents compared to White parents while the reverse was found in the US where most Asian families were Chinese and Filipino.

\section{Research Questions}

Available meta-analyses have only addressed differences between associations of harsh parenting with child outcomes between the US and countries other than the US (Gershoff \& Grogan-Kaylor, 2016a), and between African-American and European American families (Gershoff \& Grogan-Kaylor, 2016b). Thus, there is a need for a more differentiated view on regions of the globe and for including other ethnic groups (e.g., Asian American and Hispanic families). The goal of the present meta-analysis was to compare associations of harsh parenting with internalizing and externalizing problems across 10 geographic regions and four ethnic groups, based on the cultural normativeness hypothesis. Because associations of harsh parenting with internalizing symptoms tend to be weaker than associations with externalizing symptoms (Pinquart, $2017 \mathrm{a}, \mathrm{b})$, they were analyzed separately. As very small numbers of studies are available for most countries, the present meta-analysis focused on regions rather than individual countries. Based on the categorization of regions according to common cultural roots (Huntington, 1996; 
Spencer \& Thomas, 1973), ten regions were compared: North America, Central/Southern America, Western Europe (countries that have not been part of the former communist bloc), Eastern Europe/Russia, North Africa/the Arabian Peninsula, Sub-Sahara Africa, Australia/New Zealand, East Asia (e.g., China, Japan, Taiwan), South Asia (e.g., India, Bangladesh, Pakistan), and South-East Asia (e.g., Cambodia, Indonesia, Thailand). The frontiers of these regions are somewhat permeable as, for example, some formerly communist Eastern European countries have now become members of the European Union. In contrast to almost all African and Asian countries, all forms of physical punishment of children are prohibited in most Western European countries (Global Initiative to End Corporal Punishment of Children, 2020; UNICEF, 2019). Thus, the first research question asked whether associations of harsh parenting with internalizing and externalizing problems are weaker in African and Asian countries than in Western Europe.

The second research questions asked whether associations of harsh parenting with internalizing and externalizing symptoms would be stronger in countries that have legally banned all forms of physical punishment of children, in countries where physical punishment of children by their parents is less accepted and prevalent, and in the more individualistic/less collectivistic countries.

The third research question addressed ethnic differences within western countries and asked whether associations of harsh parenting with internalizing and externalizing symptoms would be stronger in Caucasian families than in families with an African ethnic background. Differences between Caucasian families and Hispanic families, as well as Asian families, were explored without stating a directional hypothesis because comparative data on the prevalence of harsh parenting in the latter groups were inconclusive (Gershoff et al., 2012; Silveira et al., 2021; Taillieu et al., 2014). While it would also be interesting to meta-analyze ethnic differences in non-western countries, there were not enough studies for doing this.

As bivariate associations between parenting and child behaviors could reflect parental effects as well as child effects (Bell, 1977; Reid et al., 2002), separate analyses of bivariate and cross-lagged associations between harsh parenting and internalizing/externalizing symptoms were computed.

\section{Methods}

\section{Sample}

Studies were found through the electronic databases PSYCINFO, ERIC, Google Scholar, and PSYNDEX [search terms: (harsh parenting OR spanking OR corporal punishment OR harsh discipline OR physical punishment) AND (parents OR mothers OR fathers) AND (internalizing problems OR externalizing problems OR delinqu* OR aggress* OR anxiety OR depress*)]. The references of the identified studies were checked for additional papers. The final search was completed on March 2, 2021. Criteria for inclusion of studies in the present meta-analysis were:

a. Correlations of harsh parenting (e.g., yelling, shouting, spanking, slapping) with internalizing problems and/or externalizing problems were reported or could be computed.

b. The mean age of the sample was $<20$ years, based on the age range of childhood and adolescence proposed by UNICEF.

c. The studies were completed before March, 2021.

\section{Studies were excluded if they}

a. provided only multivariate analyses, as these effect sizes cannot be combined with bivariate coefficients, and

b. used only a sum-score of negative parenting which also included behaviors others than harsh parenting.

The included studies were not limited to those written in English. Unpublished studies from the databases (e.g., dissertations) were included in order to minimize effects of publication bias. The search identified 1804 records. After screening and assessing for eligibility, 971 studies were included in the meta-analysis, with 41 of them not being published in English (Fig. 1). Selected characteristics of the included studies are reported in the supplementary appendices $\mathrm{A} 1$ and $\mathrm{A} 2$.

The present meta-analysis extends previous work (Pinquart, 2017a, b) by focusing on cultural similarities and differences. The meta-analysis has not been preregistered. As moderator effects of some study characteristics (e.g., age, source of information, study quality) have already been reported in previous papers, they were not included in the present study. The meta-analysis followed the PRISMA 2009 checklist. A review protocol is available from the author.

The following variables from the studies were entered: Number of children, mean age, percentage of girls, percentage of children with African, Asian, European/Caucasian, and Hispanic ethnic backgrounds, country and region of data collection, method for assessing harsh parenting, method for assessing internalizing/externalizing symptoms, support for validity of the parenting and symptom measures $(1=$ yes, $0=$ no), study design $(1=$ cross-sectional, $2=$ longitudinal $)$ and the size of bivariate and cross-lagged association of harsh parenting with internalizing/externalizing problems. Crosslagged effect sizes (that control for the pretest score of the independent variable) often had to be computed from the reported matrix of bivariate correlations. If the same effect size 
Fig. 1 PRISMA 2009 Flow Diagram

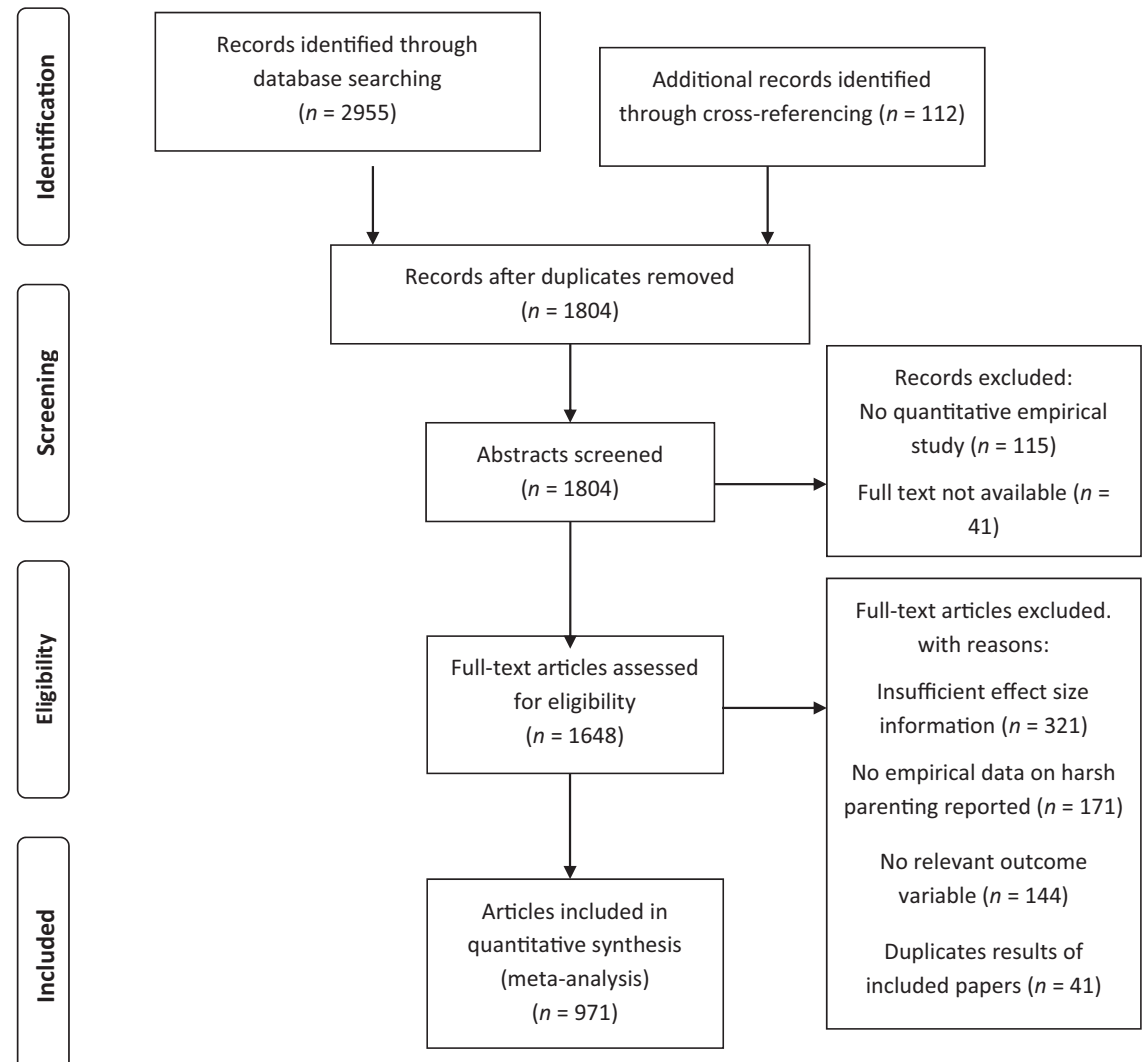

was reported in more than one paper, the effect size was coded only once. The author coded all studies. A graduate student also coded about $20 \%$ of the studies. A mean inter-rater reliability of $92 \%$ (range $88-100 \%$ ) was established; differences were resolved by discussion.

\section{Measures}

The studies assessed harsh parenting with the Parent-toChild Conflict Tactics Scale (Straus et al., 1998; 170 studies), the Parenting Scale (Arnold et al., 1993; 83 studies), the Alabama Parenting Questionnaire (Frick, 1991; 81 studies), observations (60 studies), and other related instruments (578 studies). Internalizing symptoms were assessed with the Child Behavior Problem Checklist (CBCL; Achenbach, 1991; 148 studies), the Youth Self-Report (YSR; Achenbach, 1991; 46 studies), the Strengths and Difficulties Questionnaire (SDQ; Goodman, 1997; 42 studies), as well as other related instruments (211 studies). Externalizing symptoms were measured with the CBCL (267 studies), the YSR (70 studies), the SDQ (51 studies), the Teacher Report Form (Achenbach, 1991; 40 studies), and other related instruments (440 studies).

For the individual countries in which the studies took place, national levels of four variables were extracted from the following sources: The Global Initiative to End
All Corporal Punishment of Children (2020) provided national data on whether corporal punishment in the family was prohibited in the individual countries $(2=$ yes, $1=$ no). National acceptance rates of physical punishment were taken from Straus (2010) who had asked whether it is sometimes necessary to discipline the child "with a good harsh spanking". The third International Self-Report Delinquency Study provided adolescent reports from 30 countries on whether they have been beaten, slapped, or pushed by their mothers or fathers in the past 12 months (Enzmann, 2018). Scores from Enzmann (2018) and Straus (2010) for the countries of the present meta-analysis are provided in Appendix A3. Finally, the country levels of individualism-collectivism were extracted from Hofstede Insights (2019); higher scores represent higher levels of individualism. Prevalence rates of harsh parenting from the Multiple Indicator Cluster Survey (UNICEF, 2019) could not be used because this survey had not included the countries from which most studies on associations of harsh parenting and internalizing/ externalizing problems were available, such as the U.S., China, or Canada.

\section{Statistical Analysis}

The meta-analytic procedures were similar to those of a previous meta-analysis on cultural differences in 
associations of parenting styles with child outcomes (Pinquart \& Kauser, 2018). Calculations were performed in five steps. Random-effects models with the method of moments were computed (Lipsey \& Wilson, 2001).

1. Correlations were transformed into Fisher's $z$-scores. Then, outliers that were more than two SDs from the mean of the effect sizes were recoded to the value at two SDs, based on Lipsey and Wilson (2001).

2. Weighted mean $z$-scores and $95 \%$-confidence intervals $[\mathrm{CIs}]$ were computed. The significance of the mean effect size was tested by dividing the weighted mean effect size by the standard error of the mean. Mean $z$-scores were later converted to the original metric of product-moment correlations.

3. Homogeneity of effect sizes was assessed by use of the $Q$ statistic and $I^{2}$.

4. In order to test differences between regions, an analog of the analysis of variance was used. A significant $Q$ score indicates heterogeneity between regions. Differences between two regions are significant if their $\mathrm{CIs}$ do not overlap (Lipsey \& Wilson, 2001). Weighted linear regressions (meta-regressions) were used for analyzing moderating effects of normativeness of harsh parenting.

5. Egger's test and trim-and-fill analysis were used for detecting a possible publication bias (Duval \& Tweedie, 2000).

\section{Results}

The included studies have been conducted in 76 countries, with most studies coming from the United States $(N=535)$, China $(N=67)$, Canada $(N=40)$, and the Netherlands $(N=38)$ (see Appendix A 3 for a full list of the countries). The studies provided data on 984,520 parent-child dyads. The children and adolescents had a mean age of 8.48 years $(S D=4.50)$. About $48.7 \%$ of the children were female; 133 of the included studies were unpublished. About $86.7 \%$ of the studies used community-based convenience samples. While $83.6 \%$ of the studies provided support for the validity of assessment of child symptoms, the percentage was lower for parenting measures $(60.6 \%)$, where many studies used single-item indicators of spanking frequency. The mean follow-up interval of longitudinal studies was 2.91 years $(S D=2.45)$.

\section{Regional Differences}

Because the size of bivariate associations was significantly larger in cross-sectional studies than in longitudinal studies (internalizing: $r=0.17$ vs. $r=0.11, Q(1)=42.24, p<$ 0.001 ; externalizing: $r=0.24$ vs. $r=0.18, Q(1)=76.67$, $p<0.001$ ), separate analyses were computed for both kinds of studies.

With regard to the first research question, there were significant concurrent associations of harsh parenting with internalizing and externalizing symptoms in all regions (Table 1). Nonetheless, there was significant regional variability: Associations with internalizing symptoms were stronger in East Asia than in Subsahara Africa and Western Europe. The size of this association with externalizing symptoms was stronger in South Asia than in other regions, except for Latin America. Associations were also stronger in Latin America and Subsahara Africa than in South-East Asia.

The size of longitudinal associations of initial harsh parenting with internalizing symptoms at follow-up did not differ between regions. In contrast, there was significant regional variation in the size of associations of initial harsh parenting with externalizing symptoms at follow-up, with stronger associations in North Africa/the Arabian Peninsula than in North America, East Asia, and South-East Asia. In addition, associations were stronger in North America and Western Europe than in South-East Asia.

Cross-lagged analyses showed that initial harsh parenting predicted an increase in internalizing problems in the total sample as well as in North America, Western Europe, Latin America, East Asia, and South-East Asia. Interestingly, there was a significant negative association in Sub-Sahara Africa, but this association was based on only one study and may, therefore, not be reliable. The cross-lagged association was significantly more negative in Subsahara Africa than in the other regions, except Australia/New Zealand. Initial harsh parenting predicted an increase in externalizing symptoms in North America, Western Europe, Latin America, East Asia, and North Africa/the Arabian Peninsula. Regional variation was significant, and the association was stronger in North America, Western Europe, and Latin America than in Sub-Sahara Africa.

Cross-lagged associations of initial internalizing symptoms with change in harsh parenting did not vary by region. Internalizing symptoms predicted an increase in parental harshness in North America and East Asia. Initial externalizing symptoms predicted an increase in harsh parenting in North America, Western Europe, Latin America, East Asia, and North Africa/the Arabian Peninsula. There was regional variation in the size of the associations, with associations being stronger in Western Europe than in North America and South-East Asia. With the exception of concurrent associations of harsh parenting with internalizing symptoms in South Asia, there was no significant variation of the effect sizes within regions.

Egger's tests indicated some funnel plot asymmetry in five analyses (Appendix A4). The trim-and-fill algorithm 
Table 1 Regional differences in the association of harsh parenting with internalizing and externalizing problems

\begin{tabular}{|c|c|c|c|c|c|c|c|c|c|c|c|c|c|c|}
\hline & \multirow[b]{2}{*}{$k$} & \multirow[b]{2}{*}{$r$} & \multicolumn{5}{|c|}{ Internalizing problems } & \multicolumn{7}{|c|}{ Externalizing problems } \\
\hline & & & \multicolumn{2}{|l|}{$95 \%-\mathrm{CI}$} & \multirow[t]{2}{*}{$Z$} & \multirow[t]{2}{*}{$Q$} & \multirow[t]{2}{*}{$I^{2}$} & \multirow[t]{2}{*}{$k$} & \multirow[t]{2}{*}{$r$} & \multicolumn{2}{|l|}{$95 \%$-CI } & \multirow[t]{2}{*}{$Z$} & \multirow[t]{2}{*}{$Q$} & \multirow[t]{2}{*}{$I^{2}$} \\
\hline \multicolumn{7}{|c|}{ Bivariate concurrent associations } & & & & & & & & \\
\hline All studies & 740 & 0.17 & 0.16 & 0.18 & $38.48^{\mathrm{c}}$ & 687.52 & 0 & 1432 & 0.24 & 0.23 & 0.24 & $65.24^{\mathrm{c}}$ & 1341.02 & 0 \\
\hline Regions & & & & & & $22.85^{\mathrm{b}}$ & & & & & & & $56.26^{\mathrm{c}}$ & \\
\hline North America & 444 & 0.17 & 0.16 & 0.19 & $27.99^{\mathrm{c}}$ & 384.86 & 0 & 784 & 0.23 & 0.22 & 0.24 & $43.93^{\mathrm{c}}$ & 695.67 & 0 \\
\hline Western Europe & 103 & 0.16 & 0.14 & 0.18 & $14.43^{\mathrm{c}}$ & 93.05 & 0 & 256 & 0.24 & 0.23 & 0.26 & $29.15^{\mathrm{c}}$ & 241.05 & 0 \\
\hline Eastern Europe & 17 & 0.17 & 0.12 & 0.21 & $6.55^{\mathrm{c}}$ & 12.35 & 0 & 44 & 0.25 & 0.23 & 0.30 & $14.56^{\mathrm{c}}$ & 29.52 & 0 \\
\hline Latin America & 20 & 0.14 & 0.09 & 0.18 & $5.90^{\mathrm{c}}$ & 16.78 & 0 & 34 & 0.28 & 0.24 & 0.32 & $13.53^{\mathrm{c}}$ & 29.52 & 0 \\
\hline East Asia & 78 & 0.21 & 0.19 & 0.24 & $16.41^{\mathrm{c}}$ & 80.16 & 3.9 & 160 & 0.22 & 0.20 & 0.24 & $20.83^{\mathrm{c}}$ & 140.94 & 0 \\
\hline South Asia & 8 & 0.24 & 0.16 & 0.32 & $5.74^{\mathrm{c}}$ & $18.06^{\mathrm{a}}$ & 61.2 & 27 & 0.36 & 0.31 & 0.41 & $13.79^{\mathrm{c}}$ & 30.82 & 15.6 \\
\hline South-East Asia & 10 & 0.21 & 0.14 & 0.28 & $5.69^{c}$ & 11.02 & 18.3 & 31 & 0.16 & 0.12 & 0.20 & $6.87^{\mathrm{c}}$ & 29.85 & 0 \\
\hline NA/AP & 9 & 0.19 & 0.12 & 0.26 & $5.01^{\mathrm{c}}$ & 8.25 & 0 & 35 & 0.24 & 0.21 & 0.28 & $11.61^{\mathrm{c}}$ & 34.03 & 0 \\
\hline Sub-Sahara & 18 & 0.13 & 0.08 & 0.17 & $5.18^{\mathrm{c}}$ & 18.69 & 0.9 & 23 & 0.25 & 0.21 & 0.31 & $9.27^{\mathrm{c}}$ & 28.14 & 21.8 \\
\hline Australia/ New Zeal. & 29 & 0.15 & 0.10 & 0.19 & $6.37^{\mathrm{c}}$ & 21.47 & 0 & 29 & 0.27 & 0.23 & 0.32 & $11.26^{\mathrm{c}}$ & 26.23 & 0 \\
\hline \multicolumn{15}{|c|}{ Bivariate longitudinal associations of harsh parenting $\left(t_{1}\right)$ with behavior problems $\left(t_{2}\right)$} \\
\hline All studies & 195 & 0.11 & 0.09 & 0.13 & $12.15^{\mathrm{c}}$ & 158.74 & 0 & 578 & 0.18 & 0.17 & 0.19 & $30.05^{\mathrm{c}}$ & 482.66 & 0 \\
\hline Regions & & & & & & 3.34 & & & & & & & $19.94^{\mathrm{b}}$ & \\
\hline North America & 144 & 0.10 & 0.08 & 0.11 & $10.96^{\mathrm{c}}$ & 115.42 & 0 & 417 & 0.18 & 0.17 & 0.19 & $29.03^{c}$ & 349.49 & 0 \\
\hline Western Europe & 22 & 0.13 & 0.09 & 0.16 & $6.69^{c}$ & 11.48 & 0 & 92 & 0.19 & 0.16 & 0.22 & $13.95^{\mathrm{c}}$ & 63.86 & 0 \\
\hline \multicolumn{15}{|l|}{ Eastern Europe } \\
\hline Latin America & & & & & & & & 1 & 0.08 & -0.14 & 0.29 & 0.71 & 0.00 & 0 \\
\hline East Asia & 20 & 0.12 & 0.08 & 0.16 & $6.02^{\mathrm{c}}$ & 23.42 & 18.9 & 39 & 0.14 & 0.10 & 0.18 & $6.87^{\mathrm{c}}$ & 27.36 & 0 \\
\hline \multicolumn{15}{|l|}{ South Asia } \\
\hline South-East Asia & 1 & 0.15 & 0.03 & 0.26 & $2.44^{\mathrm{a}}$ & 0.00 & 0 & 8 & 0.08 & 0.01 & 0.15 & $2.23^{\mathrm{a}}$ & 8.51 & 17.7 \\
\hline NA/AP & & & & & & & & 7 & 0.27 & 0.19 & 0.34 & $6.56^{\mathrm{c}}$ & 3.46 & 0 \\
\hline Sub-Sahara & & & & & & & & 3 & 0.06 & -0.24 & 0.35 & 0.37 & 0.49 & 0 \\
\hline Australia/New Zeal & 8 & 0.09 & 0.03 & 0.14 & $3.11^{\mathrm{b}}$ & 2.09 & 0 & 11 & 0.15 & 0.09 & 0.20 & $4.84^{\mathrm{c}}$ & 9.56 & 0 \\
\hline Harsh parenting - cha & nge of & behavior & al proble & & & & & & & & & & & \\
\hline All studies & 126 & 0.05 & 0.04 & 0.07 & $8.35^{\mathrm{c}}$ & 105.08 & 0 & 428 & 0.08 & 0.07 & 0.09 & $16.31^{\mathrm{c}}$ & 329.68 & 0 \\
\hline Regions & & & & & & $12.75^{\mathrm{a}}$ & & & & & & & $31.20^{\mathrm{c}}$ & \\
\hline North America & 92 & 0.05 & 0.04 & 0.07 & $6.81^{\mathrm{c}}$ & 71.31 & 0 & 280 & 0.08 & 0.07 & 0.09 & $13.88^{\mathrm{c}}$ & 222.09 & 0 \\
\hline Western Europe & 14 & 0.07 & 0.03 & 0.10 & $4.06^{\mathrm{c}}$ & 13.50 & 3.7 & 84 & 0.09 & 0.06 & 0.11 & $7.26^{\mathrm{c}}$ & 50.73 & 0 \\
\hline Eastern Europe & & & & & & & & & & & & & & \\
\hline Latin America & 1 & 0.08 & 0.00 & 0.16 & $1.98^{\mathrm{a}}$ & 0.00 & 0 & 1 & 0.28 & 0.18 & 0.39 & $5.13^{\mathrm{c}}$ & 0.00 & 0 \\
\hline East Asia & 13 & 0.04 & 0.01 & 0.08 & $2.41^{\mathrm{a}}$ & 7.19 & 0 & 40 & 0.06 & 0.03 & 0.09 & $3.75^{\mathrm{c}}$ & 16.39 & 0 \\
\hline South Asia & & & & & & & & & & & & & & \\
\hline South-East Asia & 1 & 0.09 & 0.02 & 0.16 & $2.40^{\mathrm{a}}$ & 0.00 & 0 & 10 & 0.03 & -0.01 & 0.07 & 1.29 & 4.12 & 0 \\
\hline NA/AP & & & & & & & & 6 & 0.10 & 0.03 & 0.17 & $2.80^{\mathrm{b}}$ & 3.21 & 0 \\
\hline Sub-Sahara & 1 & -0.10 & -0.19 & -0.00 & $-2.02^{\mathrm{a}}$ & 0.00 & 0 & 4 & -0.08 & -0.20 & 0.04 & -1.35 & 1.22 & 0 \\
\hline Australia/New Zeal & 4 & 0.01 & -0.08 & 0.11 & 0.29 & 0.33 & 0 & 3 & -0.00 & -0.11 & 0.10 & -0.02 & 0.71 & 0 \\
\hline Behavioral problems - & chan & e of hars & h parenti & & & & & & & & & & & \\
\hline All studies & 68 & 0.05 & 0.03 & 0.08 & $4.64^{\mathrm{c}}$ & 57.09 & 0 & 244 & 0.09 & 0.07 & 0.10 & $14.51^{\mathrm{c}}$ & 184.36 & \\
\hline Regions & & & & & & 3.47 & & & & & & & $18.04^{\mathrm{a}}$ & \\
\hline North America & 55 & 0.05 & 0.03 & 0.08 & $4.24^{\mathrm{c}}$ & 51.44 & 0 & 148 & 0.08 & 0.06 & 0.09 & $10.65^{\mathrm{c}}$ & 127.58 & 0 \\
\hline Western Europe & 5 & 0.01 & -0.06 & 0.08 & 0.22 & 1.49 & 0 & 60 & 0.13 & 0.10 & 0.15 & $8.97^{\mathrm{c}}$ & 30.95 & 0 \\
\hline Latin America & 1 & 0.03 & -0.11 & 0.16 & 0.37 & & 0 & 1 & 0.13 & 0.03 & 0.23 & $2.46^{\mathrm{a}}$ & 0.00 & 0 \\
\hline East Asia & 6 & 0.11 & 0.03 & 0.19 & $2.60^{\mathrm{b}}$ & 0.68 & 0 & 20 & 0.07 & 0.02 & 0.12 & $2.72^{\mathrm{b}}$ & 3.94 & 0 \\
\hline
\end{tabular}


Table 1 (continued)

\begin{tabular}{|c|c|c|c|c|c|c|c|c|c|c|c|c|c|c|}
\hline & \multirow[b]{2}{*}{$k$} & \multirow[b]{2}{*}{$r$} & \multicolumn{5}{|c|}{ Internalizing problems } & \multicolumn{7}{|c|}{ Externalizing problems } \\
\hline & & & $95 \%-\mathrm{CI}$ & & $Z$ & $Q$ & $I^{2}$ & $\bar{k}$ & $r$ & $95 \%-\mathrm{CI}$ & & $Z$ & $Q$ & $I^{2}$ \\
\hline \multicolumn{15}{|l|}{ South Asia } \\
\hline South-East Asia & & & & & & & & 5 & 0.03 & -0.03 & 0.08 & 0.90 & 0.69 & 0 \\
\hline NA/AP & & & & & & & & 6 & 0.14 & 0.07 & 0.20 & $4.07^{\mathrm{c}}$ & 2.19 & 0 \\
\hline Sub-Sahara & & & & & & & & 3 & 0.24 & -0.04 & 0.50 & 1.67 & 0.98 & 0 \\
\hline Australia/New Zeal & 1 & 0.09 & -0.38 & 0.52 & 0.35 & 0.00 & 0 & 1 & 0.08 & -0.06 & 0.22 & 1.08 & 0.00 & 0 \\
\hline
\end{tabular}

$k=$ number of effect sizes included; $r=$ weighted mean correlation coefficient; $Z=$ test for significance of $r .95 \% C I=$ lower and upper limits of 95\% confidence interval; $Q=$ test for homogeneity of effect sizes; $I^{2}=$ proportion of the observed variance that reflects variance in true effect sizes; NA/AP $=$ North Africa/Arabian Peninsula

${ }^{\mathrm{a}} p<0.05$

${ }^{\mathrm{b}} p<0.01$

${ }^{\mathrm{c}} p<0.001$

Table 2 Correlations of National Levels of Acceptance and Use of Physical Punishment, Individualism-Collectivism, and Legal Ban of all Kind of Physical Punishment in the Home

\begin{tabular}{llrr}
\hline Variables & $\begin{array}{l}\text { Acceptance of physical } \\
\text { punishment (Straus, 2010) }\end{array}$ & $\begin{array}{l}\text { Prevalence of physical punishment } \\
\text { (Enzmann, 2018) }\end{array}$ & $\begin{array}{c}\text { Individualism-collectivism } \\
\text { Legal ban }(1=\text { yes, } 0=\text { no) }\end{array}$ \\
$\begin{array}{llr}\text { Acceptance of physical punishment } \\
\text { (Straus, 2010) }\end{array}$ & $-0.40^{*}(N=26)$ & $0.52^{*}(N=27)$ & $0.31^{*}(N=68)$ \\
$\begin{array}{l}\text { Prevalence of physical punishment } \\
\text { (Enzmann, 2018) }\end{array}$ & & $-0.41^{*}(N=27)$ \\
\end{tabular}

Higher scores on the individualism-collectivism scale indicate higher individualism. $N$ indicates the number of countries. Data on legal ban were available for 75 of the 76 included countries, on acceptance and prevalence for 27 countries, and on individualism-collectivism for 69 countries ${ }^{*} p<0.05$

led to very small declines of the longitudinal association of harsh parenting with internalizing symptoms (from $r=0.11$ to $r=0.09$ ) and externalizing symptoms at follow-up (from $r=0.18$ to $r=0.17$ ) and of harsh parenting with change in externalizing symptoms (from $r=0.08$ to 0.07 ). In contrast, the association of harsh parenting with change in internalizing symptoms and the association of externalizing symptoms with change in harsh parenting slightly increased (from $r=0.05$ to $r=0.07$ and from $r=0.09$ to 0.10 ; Appendix A4).

\section{Moderator Effects of Indicators of Normativeness of Harsh Parenting}

The second research question asked whether countrylevel indicators of normativeness of harsh parenting (and of physical punishment in particular) moderated the size of associations between harsh parenting and child symptoms-namely the legal ban of physical punishment of children in the home, acceptance of physical punishment, prevalence of physical punishment, and the levels of individualism-collectivism.
Indicators of normativeness were correlated at the national level. The legal ban of physical punishment in the family was associated with lower national acceptance and prevalence rates of physical punishment, as well as with higher individualism-scores (Table 2). In addition, acceptance rates were lower in more individualistic countries.

As shown in Table 3, the bivariate associations of harsh parenting with externalizing symptoms were significantly stronger in countries that have banned physical punishment of children in the home. Two moderating effects of the national level of acceptance of physical punishment of children were identified (Table 3). Bivariate concurrent correlations of harsh parenting with externalizing symptoms and associations of externalizing symptoms with an increase in harsh parenting were weaker in countries where physical punishment was more accepted.

Two moderating effects of the national prevalence of physical punishment were statistically significant: Bivariate concurrent associations of harsh parenting with externalizing symptoms were weaker in countries with a higher prevalence of physical punishment. In addition, initial externalizing symptoms predicted a weaker increase in 
Table 3 Moderating effects of indicators of country-levels of normativeness of physical punishment and individualism/collectivism on the association of harsh parenting with internalizing and externalizing problems

\begin{tabular}{|c|c|c|c|c|c|c|c|c|c|c|}
\hline \multirow[b]{2}{*}{ Moderator } & \multicolumn{5}{|c|}{ Internalizing problems } & \multicolumn{5}{|c|}{ Externalizing problems } \\
\hline & $\bar{k}$ & $B$ & $\beta$ & $Z$ & $R^{2}$ & $k$ & $B$ & $\beta$ & $Z$ & $R^{2}$ \\
\hline \multicolumn{11}{|c|}{ Legal ban of physical punishment in the family (Global Initiative to End All Corporal Punishment of Children, 2020) } \\
\hline Bivariate concurrent assoc. & 735 & 0.012 & 0.04 & 0.99 & 0.00 & 1422 & 0.033 & 0.09 & $3.27^{\mathrm{b}}$ & 0.01 \\
\hline Bivariate longitudinal assoc. & 195 & 0.031 & 0.10 & 1.29 & 0.01 & 578 & -0.018 & -0.04 & -0.88 & 0.00 \\
\hline Harsh - change behav. probl. & 126 & 0.030 & 0.12 & 1.17 & 0.01 & 428 & 0.009 & 0.03 & 0.45 & 0.00 \\
\hline Behav. probl. - change harsh & 68 & -0.008 & -0.02 & -0.14 & 0.00 & 244 & -0.044 & -0.10 & -1.29 & 0.01 \\
\hline \multicolumn{11}{|c|}{ Acceptance of physical punishment (Straus, 2010) } \\
\hline Bivariate concurrent assoc. & 669 & 0.001 & 0.07 & 1.62 & 0.00 & 1274 & -0.001 & -0.07 & $-2.31^{\mathrm{a}}$ & 0.01 \\
\hline Bivariate longitudinal assoc. & 194 & 0.000 & -0.03 & -0.40 & 0.00 & 562 & -0.000 & -0.01 & -0.22 & 0.00 \\
\hline Harsh - change behav. probl. & 126 & -0.000 & -0.04 & -0.42 & 0.00 & 412 & -0.000 & -0.03 & -0.47 & 0.00 \\
\hline Behav. probl. - change harsh & 68 & 0.001 & 0.11 & 0.79 & 0.01 & 235 & -0.002 & -0.19 & $-2.40^{\mathrm{a}}$ & 0.03 \\
\hline \multicolumn{11}{|c|}{ National prevalence of physical punishment (Enzmann, 2018) } \\
\hline Bivariate concurrent assoc. & 487 & 0.001 & 0.02 & 0.33 & 0.00 & 1017 & -0.003 & -0.09 & $-2.67^{\mathrm{b}}$ & 0.01 \\
\hline Bivariate longitudinal assoc. & 153 & -0.003 & -0.10 & -1.04 & 0.01 & 476 & -0.001 & -0.04 & -0.73 & 0.00 \\
\hline Harsh - change behav. probl. & 94 & -0.001 & -0.08 & -0.64 & 0.01 & 347 & -0.002 & -0.09 & -1.47 & 0.01 \\
\hline Behav. probl. - change harsh & 50 & 0.004 & 0.15 & 0.99 & 0.02 & 204 & -0.004 & -0.17 & $-2.16^{\mathrm{a}}$ & 0.03 \\
\hline \multicolumn{11}{|c|}{ Individualism (Hofstede Insights, 2019) } \\
\hline Bivariate concurrent assoc. & 729 & -0.000 & -0.07 & -1.80 & 0.00 & 1415 & -0.000 & -0.03 & -1.04 & 0.00 \\
\hline Bivariate longitudinal assoc. & 194 & -0.000 & -0.10 & -1.19 & 0.00 & 578 & 0.001 & 0.10 & $2.22^{\mathrm{a}}$ & 0.01 \\
\hline Harsh - change behav. probl. & 125 & -0.000 & -0.06 & -0.62 & 0.00 & 427 & 0.000 & 0.09 & 1.46 & 0.01 \\
\hline Behav. probl. - change harsh & 68 & -0.001 & -0.13 & -0.95 & 0.02 & 244 & 0.000 & 0.03 & 0.44 & 0.00 \\
\hline
\end{tabular}

$k=$ number of studies; $B / \beta$ non-/standardized regression coefficient, $t=$ test for significance, $R^{2}=$ explained variance

${ }^{\mathrm{a}} p<0.05$

${ }^{\mathrm{b}} p<0.01$

harsh parenting if physical punishment was more prevalent in the country.

The present meta-analysis also found a moderating effect of the national level of individualism-collectivism: Longitudinal associations of harsh parenting with externalizing symptoms at follow-up were stronger in more individualistic countries.

\section{Ethnic Differences in the Association of Harsh Parenting with Child Outcomes}

The third research question asked whether the associations of harsh parenting with internalizing and externalizing problems differ in western countries between families with African, Asian, Caucasian, and Hispanic ethnic backgrounds. As shown in Table 4 , the $Q$-tests indicated that bivariate and cross-lagged associations of harsh parenting with internalizing and externalizing symptoms did not differ between these ethnic groups. Harsh parenting was concurrently associated with higher levels of both kinds of symptoms in all compared ethnic groups-with small mean effect sizes (Cohen, 1992). Higher initial harsh parenting predicted higher internalizing and externalizing symptoms at follow-up in all groups, with the exception of families with Asian ethnicities. In addition, harsh parenting predicted very small increases of internalizing symptoms in Caucasian families and in those with an African ethnic background, as well as very small increases of externalizing symptoms in Caucasian, African, and Hispanic families. Furthermore, higher levels of externalizing problems predicted an increase in harsh parenting in families with Caucasian and African ethnic backgrounds. All but one effect size were homogeneous.

\section{Discussion}

The present meta-analysis compared the size of associations of harsh parenting with internalizing and externalizing symptoms across geographic regions and ethnic groups. There were more similarities than differences across the compared groups. Bivariate associations of harsh parenting with externalizing symptoms were stronger in South Asia than in most other regions. In addition, there were some moderating effects of the legal ban of physical punishment, acceptance of physical punishment, 
Table 4 Ethnic differences in the association of harsh parenting with internalizing and externalizing problems

\begin{tabular}{|c|c|c|c|c|c|c|c|c|c|c|c|c|c|c|}
\hline & \multicolumn{7}{|c|}{ Internalizing problems } & \multicolumn{7}{|c|}{ Externalizing problems } \\
\hline & $k$ & $r$ & $95 \%-\mathrm{C}$ & & $Z$ & $Q$ & $I^{2}$ & $k$ & $r$ & $95 \%-\mathrm{CI}$ & & $Z$ & $Q$ & $I^{2}$ \\
\hline \multicolumn{6}{|c|}{ Bivariate concurrent associations } & 0.72 & & & & & & & 4.01 & \\
\hline Caucasian & 20 & 0.16 & 0.10 & 0.22 & $5.34^{\mathrm{c}}$ & 13.73 & 0 & 37 & 0.19 & 0.15 & 0.23 & $8.62^{\mathrm{c}}$ & 35.98 & 0 \\
\hline African & 14 & 0.16 & 0.10 & 0.21 & $5.44^{\mathrm{c}}$ & 6.73 & 0 & 29 & 0.16 & 0.12 & 0.21 & $6.89^{c}$ & 31.73 & 11.8 \\
\hline Hispanic & 37 & 0.19 & 0.14 & 0.23 & $7.22^{\mathrm{c}}$ & 30.40 & 0 & 43 & 0.23 & 0.18 & 0.27 & $9.67^{\mathrm{c}}$ & 29.58 & 0 \\
\hline Asian & 23 & 0.16 & 0.10 & 0.22 & $5.39^{\mathrm{c}}$ & 26.21 & 16.1 & 24 & 0.18 & 0.12 & 0.25 & $5.83^{\mathrm{c}}$ & 26.41 & 12.9 \\
\hline \multicolumn{6}{|c|}{ Bivariate longitudinal associations } & 0.16 & & & & & & & 0.91 & \\
\hline Caucasian & 5 & 0.11 & 0.04 & 0.17 & $3.20^{\mathrm{b}}$ & 0.78 & 0 & 14 & 0.15 & 0.10 & 0.20 & $5.43^{\mathrm{c}}$ & 13.82 & 0 \\
\hline African & 8 & 0.10 & 0.06 & 0.15 & $4.30^{\mathrm{c}}$ & 5.22 & 0 & 21 & 0.15 & 0.10 & 0.20 & $6.14^{\mathrm{c}}$ & 22.63 & 0 \\
\hline Hispanic & 32 & 0.09 & 0.04 & 0.15 & $3.52^{\mathrm{c}}$ & 7.05 & 0 & 41 & 0.18 & 0.13 & 0.23 & $7.13^{\mathrm{c}}$ & 16.68 & 0 \\
\hline Asian & 2 & 0.09 & -0.03 & 0.21 & 1.45 & 0.03 & 0 & 1 & 0.18 & -0.04 & 0.40 & 1.58 & 0.00 & 0 \\
\hline \multicolumn{6}{|c|}{ Harsh parenting - change behavior problems } & 0.57 & & & & & & & 1.34 & \\
\hline Caucasian & 6 & 0.02 & 0.01 & 0.04 & $2.65^{\mathrm{b}}$ & 2.43 & 0 & 10 & 0.05 & 0.02 & 0.07 & $3.43^{\mathrm{c}}$ & 12.24 & 26.5 \\
\hline African & 5 & 0.03 & 0.00 & 0.06 & $2.07^{\mathrm{a}}$ & 4.50 & 11.1 & 13 & 0.06 & 0.03 & 0.09 & $3.84^{\mathrm{c}}$ & 6.70 & 0 \\
\hline Hispanic & 17 & 0.02 & -0.01 & 0.05 & 1.16 & 2.36 & 0 & 26 & 0.05 & 0.02 & 0.08 & $2.95^{\mathrm{b}}$ & 14.74 & 0 \\
\hline Asian & 4 & 0.03 & -0.02 & 0.08 & 1.24 & 1.56 & 0 & 3 & 0.02 & -0.04 & 0.08 & 0.73 & $6.03^{\mathrm{a}}$ & 66.8 \\
\hline \multicolumn{6}{|c|}{ Behav. problems - change harsh parenting } & 0.70 & & & & & & & 4.80 & \\
\hline Caucasian & 2 & 0.01 & -0.01 & 0.03 & 1.00 & 0.00 & 0 & 6 & 0.05 & 0.02 & 0.08 & $3.30^{c}$ & 9.58 & 47.8 \\
\hline African & 2 & 0.02 & -0.02 & 0.05 & 1.11 & 0.02 & 0 & 6 & 0.08 & 0.04 & 0.11 & $4.38^{c}$ & 10.34 & 51.6 \\
\hline Hispanic & 7 & 0.02 & -0.01 & 0.05 & 1.19 & 1.41 & 0 & 12 & 0.04 & -0.00 & 0.07 & 1.80 & 8.41 & 0 \\
\hline Asian & 3 & -0.00 & -0.05 & 0.05 & -0.02 & 3.08 & 35.1 & 3 & 0.01 & -0.05 & 0.07 & 0.38 & 0.03 & 0 \\
\hline
\end{tabular}

Only studies from North America, Western Europe, and Australia were included in the analysis. $k=$ number of effect sizes included; $r=$ weighted mean correlation coefficient; $Z=$ test for significance of $r .95 \% \mathrm{CI}=$ lower and upper limits of $95 \%$ confidence interval; $Q=$ test for homogeneity of effect sizes, $I^{2}=$ proportion of the observed variance that reflects variance in true effect sizes

${ }^{\mathrm{a}} p<0.05$

${ }^{\mathrm{b}} p<0.01$

${ }^{c} p<0.001$

national prevalence of physical punishment, and level of individualism-collectivism.

Before interpreting the main results, some thoughts are needed about the validity of the data from the included studies. While the predominant use of convenience samples rather than nationally representative samples could lead to biased estimates of the prevalence of harsh parenting, this predominant sampling strategy is less relevant for the size of correlations of parenting with child outcomes as long as both variables show sufficient variation within each sample. Almost $40 \%$ of the studies had not provided support for the validity of their parenting measure, mainly when assessing the frequency of spanking with one or two items. Although these items have face validity, measurement errors tend to be larger. In fact, I had reported in an earlier study that correlations of harsh parenting with child outcomes were slightly smaller when using measures with unproven validity and reliability (Pinnquart, 2017b). When considering the quality of the data, it also has to be considered whether national bans of physical punishment could lead to an underreport of this behavior. However, data were usually collected anonymously, and available studies found substantial numbers of physical punishment despite national ban in the respective country (Enzmann, 2018).

Although there are national, regional, and ethnic differences in the acceptance and use of harsh parenting and of physical punishment in particular (Geshoff et al., 2012; Lee \& Watson, 2020; Manzoni \& Schwarzenegger, 2019; Strauss, 2010; UNICEF, 2019), associations of harsh parenting with child symptoms were found to be more similar across regions and ethnic groups. The rather universal associations with negative child outcomes may indicate that harsh parenting disregards important needs of the child, such as protection, warmth, and support of autonomy, which can lead to negative child outcomes (Global Initiative to End All Corporal Punishment of Children; Wang \& Kenny, 2014).

The mean bivariate and cross-lagged associations of harsh parenting with internalizing and externalizing symptoms were similar to the results of previous metaanalyses, although most of them had a narrower focus on physical punishment (Ferguson, 2013; Gershoff \& 
Grogan-Kaylor, 2016a; Larzerle et al., 2018; Pinquart, 2017 a, b). In contrast to Gershoff and Grogan-Kaylor (2016a), the present study found smaller effect sizes in longitudinal studies than in cross-sectional studies. Smaller longitudinal effect sizes are explained by changes in the predictor variable over time leading to a decrease of predictive power of the initial level of the independent variable, and by the fact that concurrent correlations were based on bidirectional effects of the two assessed variables (Adachi \& Willoughby, 2015).

As the included studies varied in whether they assessed harsh parenting as physical punishment and/or verbally aggressive behavior towards the child (e.g., Arnold et al., 1993; Frick, 1991; Straus et al., 1998), it is relevant to check whether the results of these studies can be combined. The fact that almost all mean effect sizes were homogeneous indicates that the results are similar across different indicators of harsh parenting. This result is not surprising as parental physical aggression towards children is often accompanied by verbal aggression. For example, Straus et al. (1998) reported that "ordinary corporal punishment" and "ordinary psychological aggression" correlated at $r=0.56$.

Although all forms of physical punishment have mostly been banned in Western Europe (Global Initiative to End Corporal Punishment of Children, 2020), the present metaanalysis did not find that the associations of harsh parenting with internalizing and externalizing symptoms were strongest in Western Europe. However, parental physical punishment has not yet been completely, legally banned in four of the fifteen Western European countries that provided data for the present meta-analysis (Global Initiative to End Corporal Punishment of Children, 2020), thus indicating acceptance or tolerance in some Western European countries. In addition, a minority of parents from western countries still uses physical punishment, despite the legal ban in their country (Enzmann, 2018), thus indicating that a legal ban does not always lead to zero acceptance. In addition, acceptance of physical punishment decreased in countries outside Western Europe (Lansford et al., 2017), thus increasing the similarity between Western European and other countries. Finally, differences between Western Europe and other regions may be smaller with regard to nonphysical forms of harsh parenting, which were also included in the present meta-analysis.

The present meta-analysis found most of the observed regional variation in studies on externalizing problems. This result indicates that cultural variations in the normativeness of harsh parenting refer to the use of this behavior for changing delinquent and aggressive behavior rather than for dealing with negative feelings (Deater-Deckard \& Dodge, 1997). The observed strongest concurrent associations of harsh parenting with externalizing problems in South Asian countries cannot be explained by cultural normativeness. Physical punishment of children tends to be widely accepted in these countries (Holden \& Ashif, 2016; Straus, 2010; UNICEF, 2019), which should-according to the cultural normativeness hypothesis-reduce aversive effects of physical punishment. Similarly, the observed strongest longitudinal bivariate association of harsh parenting with externalizing symptoms in North Africa/the Arabian Peninsula cannot be explained by cultural normativeness because physical punishment tends to be culturally accepted in these regions (Dwairy et al., 2006; Ifan, 2008). Severe punishment is very common in these areas (and in rural parts in particular; Alyahri \& Goodman, 2008; Holden \& Ashif, 2016), and more severe physical punishment has been found to lead to more severe aversive consequences (Ferguson, 2013). This might have led to the above-average associations with child outcomes in these regions.

The small negative cross-lagged associations of harsh parenting with change in internalizing symptoms in SubSahara Africa is more in line with the suggestion that harsh parenting may have less negative or even some positive effects if it is culturally accepted, as many parents from that region physically punish their children (UNICEF, 2019). The observed smaller association of externalizing problems with change in harsh parenting in South-East Asia might be related to the higher involvement of nonparental caregivers who intervene after externalizing behavior instead of the parents (Huang et al., 2015).

It is necessary to analyze moderating effects of indicators of the normativeness of harsh parenting at the country-level because comparative studies found some variation in the use and acceptance of physical punishment within the compared regions (Enzmann, 2018; Manzoni \& Schwarzenegger, 2019; Straus, 2010; UNICEF, 2019). Bivariate analyses found some support for the suggestion that harsh parenting would show weaker associations with child outcomes if physical punishment is more accepted and prevalent in the individual country. This could mean that higher cultural acceptance increases the willingness to use harsh parenting in response to child symptoms (e.g., when the child misbehaves) and/or that harsh parenting has less or even no negative consequences on child outcomes if being culturally accepted (Deater-Deckard \& Dodge, 1997; Lansford et al., 2005). Cross-lagged analyses supported only the former assumption. Thus, the present data indicate that cultural acceptance of physical punishment affects the reactive use of harsh parenting in response to externalizing behavior. However, as most tests for moderator effects of acceptance and prevalence of physical punishment were nonsignificant, the data indicate more similarities than differences. More moderating effects may emerge if representative national data on acceptance and prevalence of different forms of harsh parenting become available for all 
countries, and if data on acceptance/use and correlates of forms of harsh parenting are collected from the same samples. Such moderating effects have been found in some studies (Gershoff et al., 2010; Liu \& Wang, 2018) but not in others (Alampay et al., 2017).

Only one out of eight analyses found empirical support for the suggestion that children from more collectivistic countries would suffer less from harsh parenting (Irfan, 2008; Rudy \& Grusec, 2006). As social harmony is highly valued in collectivist societies (Hofstede et al., 2010), harsh parenting does not satisfy the child's need for harmony, acceptance, and protection, which probably contributes to negative effects of harsh parenting in collectivistic countries.

The present meta-analysis extends the work of Gershoff and Grogan-Kaylor (2016b) by showing that, in Western countries, associations of harsh parenting with internalizing and externalizing problems are not only similar in families with Caucasian and African ethnic backgrounds, but also in those with Hispanic and Asian backgrounds. The observed similarity could be based on the fact that associations of harsh parenting with child outcomes are already rather similar across the regions of origin and on processes of acculturation that further increase similarities between ethnic groups within the individual country (Ho, 2014).

\section{Limitations and Conclusions}

Some limitations of the present meta-analysis must be mentioned: First, the studies addressed different forms of harsh parenting. However, as almost all effect sizes were homogeneous, the results were similar across the combined studies. Second, although harsh parenting was related to higher internalizing and externalizing symptoms in all regions, it could not be tested whether this is also true for each individual country. Unfortunately, the literature search only found relevant studies from about $39 \%$ of the countries in the world. Third, linear associations of harsh parenting with child outcomes were analyzed. A few studies indicate that harsh parenting may have a nonlinear relationship with externalizing problems (e.g., Stoolmiller et al., 1997). Fourth, data on legal ban, acceptance, and prevalence refer only to physical punishment, although many included studies had assessed harsh parenting more broadly. In addition, national data on acceptance/use of physical punishment and on associations of harsh parenting with internalizing/externalizing problems usually did not come from the same studies. Both factors reduce the size of moderating effects. Fifth, national data on the prevalence and acceptance of harsh physical punishment were only available for less than half of the countries that had provided studies for the present meta-analysis. The national samples that provided data on acceptance and use of harsh parenting were probably not representative for all parents of the individual countries. In addition, data on acceptance, use, and the legal ban of physical punishment and on collectivism-individualism were only available from one point of measurement, while the included studies were completed at different times. Sixth, only one source of differences within countries was addressed-ethnicity. Finally, the analysis of correlational data does not allow for drawing causal conclusions, as unmeasured third variables may explain, at least in part, the observed associations.

Despite these limitations, several conclusions can be drawn. First, although there is some regional variability in the association of harsh parenting with child symptoms, there are more similarities than differences. When forms of harsh parenting are more common in a particular region or ethnic group (Geshoff et al., 2012; Lee \& Watson, 2020; Manzoni \& Schwarzenegger, 2019; Strauss, 2010; UNICEF, 2019), this does not necessarily mean that harsh parenting will have less aversive effects. The present metaanalysis found no support for the assumption that higher cultural acceptance of physical punishment weakens negative effects of harsh parenting on change in child outcomes. Second, the data indicate that cultural acceptance of physical punishment promotes the reactive use of harsh parenting in response to externalizing symptoms of the child. Third, as harsh parenting was concurrently associated with more internalizing and externalizing symptoms in all regions of the globe and in all compared ethnic groups, the present results indicate that parents should not use harsh parenting. Multimodal interventions aimed at reducing harsh parenting may include public education campaigns that inform the public about negative effects of harsh parenting on the child, and parenting programs that teach nonharsh forms of parenting. The best available evidence for intervention effects on the reduction of parental physical punishment comes from indicated interventions with parents who have used more severe forms of harsh physical punishment in the past (e.g., Parent-Child Interaction Therapy), and from selective prevention for parents at risk, such as the Healthy Families home visitation program (Gershoff et al., 2017).

Fourth, with regard to future research needs, more longitudinal research is needed from most regions for separating parent and child effects. In particular, the observed association of harsh parenting with a decrease of internalizing symptoms in Sub-Sahara Africa calls for more studies that test whether this result can be replicated. Because some of the observed regional differences in the association of harsh parenting with child outcomes could not be explained by cultural normativeness, more crossnational research is needed that identifies other sources of variability across countries and regions. 
Funding Open Access funding enabled and organized by Projekt DEAL.

\section{Compliance with Ethical Standards}

Conflict of Interest The author declares that he has no potential conflicts of interest. No funding was received to assist with the preparation of this manuscript. The author did not collect data from human participants and/or animals. No formal ethical consent was needed for the use of the public data collected by other researchers.

Publisher's note Springer Nature remains neutral with regard to jurisdictional claims in published maps and institutional affiliations.

Open Access This article is licensed under a Creative Commons Attribution 4.0 International License, which permits use, sharing, adaptation, distribution and reproduction in any medium or format, as long as you give appropriate credit to the original author(s) and the source, provide a link to the Creative Commons license, and indicate if changes were made. The images or other third party material in this article are included in the article's Creative Commons license, unless indicated otherwise in a credit line to the material. If material is not included in the article's Creative Commons license and your intended use is not permitted by statutory regulation or exceeds the permitted use, you will need to obtain permission directly from the copyright holder. To view a copy of this license, visit http://creativecommons. org/licenses/by/4.0/

\section{References}

Achenbach, T. M. (1991). Integrative Guide for the 1991 CBCL/4 \pm 18 , YSR, and TRF Profiles. University of Vermont, Department of Psychiatry.

Adachi, P., \& Willoughby, R. (2015). Interpreting effect sizes when controlling for stability effects in longitudinal autoregressive models. European Journal of Developmental Psychology, 12(1), 116-128. https://doi.org/10.1080/17405629.2014.963549.

Alampay, L. P., Godwin, J., Lansford, J. E., Bombi, A. S., Bornstein, M. H., Chang, L., \& Bacchini, D. (2017). Severity and justness do not moderate the relation between corporal punishment and negative child outcomes. International Journal of Behavioral Development, 41(4), 491-502. https://doi.org/10. $1177 / 016502541769785$.

Alyahri, A., \& Goodman, R. (2008). Harsh corporal punishment of Yemeni children: Occurrence, type and associations. Child Abuse \& Neglect, 32(8), 766-773. https://doi.org/10.1016/j.chia bu.2008.01.001.

Arnold, D. S., O’Leary, S. G., Wolff, L. S., \& Acker, M. M. (1993). The Parenting Scale: A measure of dysfunctional parenting in discipline situations. Psychological Assessment, 5(2), 137-144. https://doi.org/10.1037/1040-3590.5.2.137.

Bell, R. Q. (1977). Socialization findings reexamined. In R. Q. Bell \& L. V. Harper (Eds.), Child effects on adults (pp. 53-84). Erlbaum.

Cohen, J. (1992). A power primer. Psychological Bulletin, 112(1), 155-159. https://doi.org/10.1037/0033-2909.112.1.155.

Deater-Deckard, K., \& Dodge, K. A. (1997). Externalizing behavior problems and discipline revisited: Nonlinear effects and variation by culture, context, and gender. Psychological Inquiry, 8(3), 161-175. https://doi.org/10.1207/s15327965pli0803_1.

Duval, S., \& Tweedie, R. (2000). Trim and fill: A simple funnel-plotbased method of testing and adjusting for publication bias in meta-analysis. Biometrics, 56(2), 455-463. https://doi.org/10. 1111/j.0006-341X.2000.00455.x.
Dwairy, M., Achoui, M., Abouserie, R., \& Farah, A. (2006). Parenting styles, individuation, and mental health of Arab adolescents: A third cross-regional research study. Journal of CrossCultural Psychology, 37(3), 262-272. https://doi.org/10.1177/ 0022022106286924.

Enzmann, D.(2018). Die Verbreitung von körperlicher Elterngewalt und Misshandlung im internationalen Vergleich: Ergebnisseder dritten International Self-Report Delinquency (ISRD-3) Studie [Prevalence of parental physical violence and misuse ininternational comparison: Data from the third International Self-Report Delinquency study]. Rechtspsychologie, 4, 456-475.https://doi. org/10.5771/2365-1083-2018-4-456.

Ferguson, C. J. (2013). Spanking, corporal punishment and negative long-term outcomes: A meta-analytic review of longitudinal studies. Clinical Psychology Review, 33(1), 196-208. https://doi. org/10.1016/j.cpr.2012.11.002.

Fréchette, S., \& Romano, E. (2015). Change in corporal punishment over time in a representative sample of Canadian parents. Journal of Family Psychology, 29(4), 507-517. https://doi.org/10.1037/fa $\mathrm{m} 0000104$.

Frick, P. J. (1991). The Alabama Parenting Questionnaire. Unpublished manuscript, University of Alabama.

Gershoff, E. T. (2002). Corporal punishment by parents and associated child behaviors and experiences: A meta-analytic and theoretical review. Psychological Bulletin, 128(4), 539-579. https://doi.org/ 10.1037//0033-2909.128.4.539.

Gershoff, E. T., \& Grogan-Kaylor, A. (2016a). Spanking and child outcomes: Old controversies and new meta-analyses. Journal of Family Psychology, 30(4), 453-469. https://doi.org/10.1037/fam0000191.

Gershoff, E. T., \& Grogan-Kaylor, A. (2016b). Race as a moderator of associations between spanking and child outcomes. Family Relations, 65(3), 490-501. https://doi.org/10.1111/fare.12205.

Gershoff, E. T., Lee, S. J., \& Durrant, J. E. (2017). Promising intervention strategies to reduce parents' use of physical punishment. Child Abuse \& Neglect, 71(1), 9-23. https://doi.org/10.1016/j. chiabu.2017.01.0017.

Gershoff, E. T., Lansford, J. E., Sexton, H. R., Davis-Kean, P., \& Sameroff, A. J. (2012). Longitudinal links between spanking and children's externalizing behaviors in a national sample of White, Black, Hispanic, and Asian American families. Child Development, 83(3), 838-843. https://doi.org/10.1111/j.1467-8624.2011.01732.x.

Gershoff, E. T., Grogan-Kaylor, A., Lansford, J. E., Chang, L., Zelli, A., Deater-Deckard, K., \& Dodge, K. A. (2010). Parent discipline practices in an international sample: Associations with child behaviors and moderation by perceived normativeness. Child Development, 81(2), 487-502. https://doi.org/10.1111/j.14678624.2009.01409.x.

Global Initiative to End All Corporal Punishment of Children (2020). Global progress towards prohibiting all corporal punishment. Retrieved January 30, 2020, from https:// endcorporalpunishment.org.

Goodman, R. (1997). The strengths and difficulties questionnaire: A research note. Journal of Child Psychology and Psychiatry, 38(5), 581-586. https://doi.org/10.1111/j.1469-7610.1997.tb01545.5.

Grusec, J. E., \& Goodnow, J. J. (1994). Impact of parental discipline methods on the child's internalization of values: A reconceptualization of current points of view. Developmental Psychology, 30 (1), 4-19. https://doi.org/10.1037/0012-1649.30.1.4.

Hinnant, J. B., Erath, S. A., \& El-Sheikh, M. (2015). Harsh parenting, parasympathetic activity, and development of delinquency and substance use. Journal of Abnormal Psychology, 124(1), 137-151. https://doi.org/10.1037/abn0000026.

Ho, G. W. K. (2014). Acculturation and its implications on parenting for Chinese immigrants: A systematic review. Journal of Transcultural Nursing, 25(2), 145-158. https://doi.org/10.1177/ 1043659613515720. 
Hofstede Insights (2019). Compare countries. Retrieved March 31, 2019, from https://www.hofstede-insights.com/product/comparecountries.

Hofstede, G., Hofstede, G. J., \& Minkow, M. (2010). Cultures and organizations: Software of the mind (3rd ed.). McGraw-Hill.

Holden, S. W., \& Ashif, R. (2016). Children's right to safety: The problem of corporal punishment in Pakistan. In S. Deb (ed.). Child safety, welfare and well-being: Issues and challenges (pp. 59-74). Springer.

Huang, L. A., Lam, T., Yeoh, B. S. A., \& Graham, E. (2015). Transnational migration, changing care arrangements and left-behind children's responses in South-east Asia. Children's Geographies, 13(3), 263-277. https://doi.org/10.1080/14733285.2015.972653.

Huntington, S. P. (1996). The clash of civilizations and the remaking of world order. Simon \& Schuster.

Irfan, S. (2008). Childrearing practices among South Asian muslims in Britain: The cultural context of physical punishment. Journal of Muslim Minority Affairs, 28(1), 147-161. https://doi.org/10.1080/ 13602000802011192.

Janson, S., Lanberg, B., \& Svensson, B. (2010). Sweden: A 30-year ban on physical punishment of children. In J. E. Durrant \& A. B. Smith (eds.), Global pathways to abolishing physical punishment (pp. 241-254). Routledge.

Lansford, J. E., Cappa, C., Putnick, D., Bornstein, H. H., DeaterDeckard, K., \& Bradley, R. H. (2017). Change over time in parents' beliefs about and reported use of corporal punishment in eight countries with and without legal bans. Child Abuse \& Neglect, 71 (1), 44-55. https://doi.org/10.1016/j.chiabu.2016.10.016.

Lansford, J. E., Chang, L., Dodge, K. A., Malone, P. S., Oburu, P., Palmerus, K., \& Quinn, N. (2005). Physical discipline and children's adjustment: Cultural normativeness as a moderator. Child Development, 76(6), 1234-1246. 10.111/j.14678624.2005.00847.x

Lansford, J. E., \& Dodge, K. A. (2008). Cultural norms for adult corporal punishment of children and societal rates of endorsement and use of violence. Parenting, 8(3), 257-270. https://doi.org/10. 1080/15295190802204843.

Larzelere, R. E., Gunnoe, M. L., \& Ferguson, C. J. (2018). Improving causal inferences in meta-analyses of longitudinal studies: Spanking as an illustration. Child Development, 89(6), 2038-2050. https://doi.org/10.1111/cdev.13097.

Lee, Y., \& Watson, M. W. (2020). Corporal punishment and child aggression: Ethnic-level family cohesion as a moderator. Journal of Family Violence, 35(15-16), 2687-2710. https://doi.org/10. $1177 / 0886260517704227$

Lipsey, M. W., \& Wilson, D. B. (2001). Practical meta-analysis. Sage.

Liu, L., \& Wang, M. (2018). Parental harsh discipline and adolescent problem behavior in China: Perceived normativeness as a moderator. Child Abuse \& Neglect, 86(1), 1-9. https://doi.org/10. 1016/j.chiabu.2018.09.009.

Mah, J. W. T., \& Johnston, C. (2012). Cultural variations in mothers' acceptance of and intent to use behavioral child management techniques. Journal of Child and Family Studies, 21, 486-497. https://doi.org/10.1007/s10826-011-9502-z.

Manzoni, P., \& Schwarzenegger, K. (2019). The influence of earlier parental violence on juvenile delinquency: The role of social bonds, self-control, delinquent peer association and moral values as mediators. European Journal of Criminology \& Policy Research, 25, 225-239. https://doi.org/10.1007/s10610-018-9392-3.

Miller-Perrin, C., \& Perrin, R. (2018). Physical punishment of children by US parents: moving beyond debate to promote children's health and well-being. Psicologia: Reflexão e Crítica, 31, 16 https://doi.org/10.1186/s41155-018-0096-x.

Pinquart, M. (2017a). Associations of parenting dimensions and styles with internalizing symptoms in children and adolescents: A metaanalysis. Marriage \& Family Review, 53(7), 613-640. https://doi. org/10.1080/01494929.2016.1247761.

Pinquart, M. (2017b). Associations of parenting dimensions and styles with externalizing problems of children and adolescents: An updated meta-analysis. Developmental Psychology, 53(5), 873-932. https://doi.org/10.1037/dev0000295.

Pinquart, M., \& Kauser, R. (2018). Do the associations of parenting styles with behavior problems and academic achievement vary by culture? Results from a meta-analysis. Cultural Diversity and Ethnic Minority Psychology, 24(1), 75-100. https://doi.org/10. 1037/cdp0000149.

Reid, J. B., Patterson, G. R., \& Snyder, J. (eds.) (2002). Antisocial behavior in children and adolescents: A developmental analysis and model for intervention. American Psychological Association.

Rohner, R. P., Bourque, S. L., \& Elordi, C. A. (1996). Children's perceptions of corporal punishment, caretaker acceptance, and psychological adjustment in a poor, biracial southern community. Journal of Marriage and the Family, 58(4), 842-852. https://doi. org/10.2307/353974.

Rudy, D., \& Grusec, J. E. (2006). Authoritarian parenting in individualist and collectivist groups: Associations with maternal emotion and cognition and children's self-esteem. Journal of Family Psychology, 20(1), 68-78. https://doi.org/10.1037/0893-3200.20.1.68.

Silveira, F., Shafer, K., Dufur, M. J., \& Roberson, M. (2021). Ethnicity and parental discipline practices: A cross-national comparison. Journal of Marriage and Family, 83(3), 644-666. https://doi.org/ 10.1111/jomf.12715.

Spencer, J. E., \& Thomas, W. L. (1973). Introducing cultural geography. Wiley.

Stoolmiller, M., Patterson, G. R., \& Snyder, J. (1997). Parental discipline and child antisocial behavior: A contingency-based theory and some methodological refinements. Psychological Inquiry, 8 (3), 223-229. https://doi.org/10.1207/s15327965pli0803_12.

Straus, M. (2010). Prevalence, societal causes, and trends in corporal punishment by parents in world perspective. Law and Contemporary Problems, 73(2), 1-30.

Straus, M. A., Hamby, S. L., Finkelhor, D., Moore, D. W., \& Runyan, D. (1998). Identification of child maltreatment with the parentchild conflict tactic scales: Development and psychometric data for a national sample of American parents. Child Abuse and Neglect, 22(4), 249-270. https://doi.org/10.1016/S0145-2134(97) 00174-9.

Taillieu, T. L., Afifi, A.-O., Mota, N., Keyes, K. M., \& Sareen, J. (2014). Age, sex, and racial differences in harsh physical punishment: Results from a nationally representative US sample. Child Abuse \& Neglect, 38(12), 1885-1894. https://doi.org/10. 1016/j.chiabu.2014.10.020.

UNICEF (2019). Global databases: Violent discipline. Retrieved January 30, 2020, from https://data.unicef.org.

Wang, M., \& Liu, L. (2018). Reciprocal relations between harsh discipline and children's externalizing behavior in China: A 5-year longitudinal study. Child Development, 89(1), 174-187. https:// doi.org/10.1111/cdev.12724.

Wang, M.-T., \& Kenny, S. (2014). Parental physical punishment and adolescent adjustment: Bidirectionality and the moderation effects of child ethnicity and parental warmth. Journal of Abnormal Child Psychology, 42(5), 717-730. https://doi.org/10. 1007/s10802-013-9827-8. 